\title{
Subacute and chronic, non-specific back and neck pain: cognitive-behavioural rehabilitation versus primary care. A randomized controlled trial Odd Lindell*, Sven-Erik Johansson and Lars-Erik Strender
}

Address: Center for Family and Community Medicine, Karolinska Institutet, Alfred Nobels allé 12, SE-141 83 Huddinge, Sweden

Email: Odd Lindell* - odd.lindell@ki.se; Sven-Erik Johansson - sven-erik.johansson@ki.se; Lars-Erik Strender - lars-erik.strender@ki.se

* Corresponding author

Published: 30 December 2008

BMC Musculoskeletal Disorders 2008, 9:172 doi:10.1186/147/-2474-9-172

This article is available from: http://www.biomedcentral.com//47/-2474/9//72

(C) 2008 Lindell et al; licensee BioMed Central Ltd.

This is an Open Access article distributed under the terms of the Creative Commons Attribution License (http://creativecommons.org/licenses/by/2.0), which permits unrestricted use, distribution, and reproduction in any medium, provided the original work is properly cited.
Received: 23 May 2008

Accepted: 30 December 2008

\begin{abstract}
Background: In the industrial world, non-specific back and neck pain (BNP) is the largest diagnostic group underlying sick-listing. For patients with subacute and chronic (= full-time sicklisted for 43 - 84 and 85 - 730 days, respectively) BNP, cognitive-behavioural rehabilitation was compared with primary care. The specific aim was to answer the question: within an 18-month follow-up, will the outcomes differ in respect of sick-listing and number of health-care visits?
\end{abstract}

Methods: After stratification by age ( $\leq 44 / \geq 45$ years) and subacute/chronic BNP, 125 Swedish primary-care patients were randomly allocated to cognitive-behavioural rehabilitation (rehabilitation group) or continued primary care (primary-care group). Outcome measures were Return-to-work share (percentage) and Return-to-work chance (hazard ratios) over 18 months, Net days (crude sick-listing days $\times$ degree), and the number of Visits (to physicians, physiotherapists etc.) over 18 months and the three component six-month periods. Descriptive statistics, Cox regression and mixed-linear models were used.

Results: All patients: Return-to-work share and Return-to-work chance were equivalent between the groups. Net days and Visits were equivalent over 18 months but decreased significantly more rapidly for the rehabilitation group over the six-month periods $(p<.05)$. Subacute patients: Return-to-work share was equivalent. Return-to-work chance was significantly greater for the rehabilitation group (hazard ratio 3.5 [95\%CII.00I - 12.2]). Net days were equivalent over 18 months but decreased significantly more rapidly for the rehabilitation group over the six-month periods and there were 3 I days fewer in the third period. Visits showed similar though non-significant differences and there were half as many in the third period. Chronic patients: Return-to-work share, Return-to-work chance and Net days were equivalent. Visits were equivalent over 18 months but tended to decrease more rapidly for the rehabilitation group and there were half as many in the third period (non-significant).

Conclusion: The results were equivalent over 18 months. However, there were indications that cognitive-behavioural rehabilitation in the longer run might be superior to primary care. For subacute BNP, it might be superior in terms of sick-listing and health-care visits; for chronic BNP, in terms of health-care visits only. More conclusive results concerning this possible long-term effect might require a longer follow-up.

Trial registration: NCT00488735. 


\section{Background}

In Sweden, as all over the industrial world, back and neck pain is the largest diagnostic group underlying sick-listing [1]. The vast majority consists of non-specific back and neck pain (BNP) that requires no specific surgical, rheumatological or neurological treatment [2].

As $93 \%$ of the societal costs of back and neck pain are connected with sick-listing [3], return-to-work is crucial [4]. However, there is a lack of consistency and comprehensiveness in return-to-work measurements [5]. While earlier studies compared the return-to-work share at a specific time point, for example one year after baseline [6], later research has evaluated the time of return-to-work in survival analyses $[7,8]$. Another important issue is the health-care utilization needed to achieve certain treatment results. In that respect, a frequently-used outcome measure is the number of health-care visits $[9,10]$.

Concerning treatment of BNP, the 1990s saw a breakthrough for the biopsychosocial model, which pinpoints time off work as an important disabling factor. Acute, subacute and chronic BNP are defined as BNP with full-time sick-listing for 0 - 21 days, $22-84$ days and more than 12 weeks, respectively [11]. Acute BNP is managed by continuing ordinary activities as normally as possible, and manipulation if necessary. In cases of subacute and chronic BNP, multidisciplinary rehabilitation should be considered [12]. Multidisciplinary treatment includes a physician's consultation in addition to psychological, social or vocational intervention or a combination of these [13]. The three key components of successful multidisciplinary rehabilitation programmes for BNP are: reactivation and progressive increase in activity levels, addressing dysfunctional beliefs and behaviour by a cognitive-behavioural therapeutic approach, and occupational interventions [4]. Concerning back pain, programmes including these items have shown good results in several studies [7,14-17]. Randomized controlled trials have concerned patients with subacute back pain only $[7-9,14,15,17,18]$, mixed groups with subacute or chronic back pain $[16,19]$ or patients with chronic back pain only [20]. There is a serious lack of evidence concerning the rehabilitation of neck pain [13]. We have found no randomized controlled trial in which the same programme was offered to patients who were stratified by subacute and chronic BNP.

The high frequency of relapses after rehabilitation of BNP is associated with inadequate follow-ups. A short program might fail to achieve long-standing behavioural changes [21]. In the 1990s the vast majority of rehabilitation programs in Sweden were comparatively short, with a fixed duration averaging six weeks [22].
Primary care is the appropriate source of treatment for BNP [12]. In Sweden, however, notwithstanding clinical guidelines, only a small minority of individuals with subacute and chronic BNP receive multidisciplinary rehabilitation [23]. One reason might be the relative lack of family doctors. While the total number of Swedish physicians meets international standards, there are proportionately fewer physicians within primary care: the density of family doctors is .5 per 1000 population, compared with an OECD (Organisation for Economic Co-operation and Development) average of .8 [24].

Our project started in 2000 with the aim of comparing a multidisciplinary programme of cognitive-behavioural rehabilitation for subacute and chronic BNP with primary care. The specific aim of this study was to answer the question: within an 18-month follow-up, will the outcomes differ in terms of sick-listing and number of health-care visits?

\section{Methods}

\section{Sick-listing in Sweden}

In Sweden, publicly provided, tax-financed social insurance compensates loss of income due to illness. The ultimate decisions about sick-listing benefits, including sickness benefit, rehabilitation benefit, temporary disability pension and disability pension, are made by the Social Insurance Agency. For sick-listing exceeding seven calendar days, a physician's certificate is required. The certificate comprises a detailed description of symptoms and signs and a recommendation of the degree $(.25, .50, .75$ or 1.00 (= full-time)) and duration of sick-listing.

\section{Participants}

The rehabilitation centre of this study was situated at Haninge, a municipality 25 kilometres south-east of Stockholm city. As the centre was well known to the local residents, the study participants were recruited within the primary care of the adjoining municipalities. One-hundred-and-twenty five patients were recruited by 42 family doctors at 12 health centres.

The criteria for inclusion: 1 . Working age up to and including 59 years. 2. Sick-listed full-time for BNP at least six weeks (42 days) and at most two years (730 days). 3. Able to fill in forms. The criteria for exclusion: 1. Temporary disability pension or disability pension being paid or in preparation. 2. A primary need for a hospital specialist (for example, operation for slipped disc). 3. Pregnancy and diseases (other than BNP) that might make rehabilitation impracticable (for example, advanced pulmonary disease). 4. Whiplash-associated disorders as a primary obstacle to working. 5. Previous rehabilitation at the rehabilitation centre. 6 . Other multidisciplinary rehabilitation current or planned. 


\section{Interventions}

One treatment group was allocated to cognitive-behavioural rehabilitation at the rehabilitation centre (rehabilitation group). The other treatment group was allocated to continued primary care (primary-care group).

\section{Cognitive-behavioural rehabilitation}

The rehabilitation centre was opened in 1991 within Stockholm County Council. From 2002 it operated as a private company and the number of rehabilitation teams was decreased from four to one, comprising four team members: a physician (OL), a physiotherapist trained in manual therapy, a psychologist or a social worker trained in cognitive-behavioural therapy and a health-care adviser. Manual therapy includes manipulation, mobilisation and stabilizing training [25]. The centre used a cognitive-behavioural programme with the aim of achieving the maximal degree of work ability lasting for at least 30 consecutive days. Work ability was inversely proportional to sick-listing, which is the definition used by the Social Insurance Agency. Work abilities of 1.00 (= full-time), .75, .50 and .25 corresponded to sick-listings of $0, .25, .50$ and .75 , respectively. Zero work ability equalled full-time sicklisting. Possible relapses were met by individual and, when needed, long rehabilitation periods. The program is described in Table 1.

Participation in the rehabilitation group did not exclude the patient from seeking other care, including primary care, during the follow-up period.

\section{Primary care}

The hubs of Swedish primary care are the health centres. They serve the local population and cater to its needs, with no restrictions as to illness, age or patient category, for basic medical treatment, nursing, preventive work or rehabilitation that does not require the medical and technical resources of hospitals or other special competences [26]. Most primary care in Sweden is publicly provided. Only a quarter is privately conducted [27]. Overall medical responsibility belongs to the family doctor. The 12 health centres in this study were situated in the municipalities of Tyresö, Huddinge, Stockholm and Nynäshamn. Ten of the centres were publicly provided, two were private. In total, they engaged 84 family doctors and served a population of 148,000 individuals, equivalent to barely .6 family doctors per 1000 population. Besides family doctors, their staff consisted of physiotherapists, nurses, assistant nurses, occupational therapists and social workers. Besides management at the health centre, primary care could include referral to consultation by, for example, an orthopedist or a neurologist.

Participation in the primary-care group excluded the patient from turning to the rehabilitation centre during the follow-up period but not from any other health-care, including multidisciplinary rehabilitation at units other than the rehabilitation centre.

\section{Outcome measures}

Return-to-work share

The percentage of patients who regained any degree of work ability for at least 30 days in succession over 18 months. This was the primary outcome measure. Secondary outcome measures were:

\section{Return-to-work chance}

The chance, as expressed in hazard ratios, of achieving any degree of work ability over 18 months, irrespective of the duration of that work ability.

\section{Net days}

Sick-listing, expressed in whole days, over 18 months and the three component six-month periods. Net days $=$ crude days $\times$ degree [28].

\section{Visits}

The total number of health-care visits over 18 months and over the three component six-month periods. Visits comprised consultations at the rehabilitation centre, within primary care and other care, including alternative-care providers, but excluded consultations relating to multidisciplinary rehabilitation at units other than the rehabilitation centre.

\section{Analyses and statistics}

Except for descriptive statistics [29,30], Cox regression and mixed-linear models were used.

Return-to-work chance was compared by a Cox regression analysis for recurrent events with event dependence and a time interaction with the exposure variable (i.e. rehabilitation group or primary-care group) and is presented as hazard ratios with $95 \%$ confidence intervals [31]. It was analysed at six, 12 and 18 months.

Net days and Visits in the first, second and third six-month periods were outcome variables in two separate mixedlinear models. In the models, the main effects of three explanatory variables and two interaction terms were compared using a random intercept model of the unstructured covariance type on the group level and time as repeated factor [32]. The explanatory variables were time (i.e. six-month period 1, 2 or 3), rehabilitation group or primary-care group, and subacute or chronic patient. The interaction terms were time $\times$ rehabilitation group or primary-care group and time $\times$ rehabilitation group or primary-care group $\times$ sub-acute or chronic. The models were also adjusted for possible baseline characteristics with significant differences between the groups. The analyses were 
Table I: Cognitive-behavioural rehabilitation.

\begin{tabular}{|c|c|c|}
\hline Staff category & Investigation and treatment phase, $2-8$ weeks & Frequency \\
\hline Physician & $\begin{array}{l}\text { Mapping out of medical obstacles to working. Handling of the sick- } \\
\text { listing. If needed, prescription of drugs (antidepressants, analgesics } \\
\text { etc.) and injections of cortisone (in shoulder- or hip-muscle } \\
\text { attachments etc.)[25]. }\end{array}$ & I - 2 (consultations)/week. \\
\hline Physiotherapist & $\begin{array}{l}\text { Mapping out of biomechanical obstacles to working including a visit } \\
\text { to the work place [14]. } \\
\text { Start of graded activity: the patient first carried out an activity } \\
\text { measurable in minutes, metres, etc., for example a walk, until the } \\
\text { pain increased. The starting level was about } 25 \% \text { below that. A } \\
\text { gradual increase of the activity was decided on check-ups, the final } \\
\text { aim being to manage the load in a job, for the unemployed an } \\
\text { imaginary one [14]. } \\
\text { If needed, manual therapy [25]. }\end{array}$ & $\begin{array}{l}2-3 \text { consultations. } \\
\text { I/week. } \\
\text { I/week. }\end{array}$ \\
\hline Psychologist or social worker & $\begin{array}{l}\text { Mapping out of psychosocial obstacles to working. Cognitive- } \\
\text { behavioural therapy focussed on anxiety and depression [46]. }\end{array}$ & I/week. \\
\hline \multirow[t]{2}{*}{ Health-care adviser } & Start of education in applied relaxation [46]. & I/week for $6-8 \mathrm{w}$ \\
\hline & Action phase, 2 - 8 months & \\
\hline Team & $\begin{array}{l}\text { Conference that produced a written rehabilitation plan with: } \\
\text { I. Final aim = the optimal degree of work ability that could be } \\
\text { achieved and maintained for at least } 30 \text { consecutive days. } \\
\text { 2. Partial aims concerning functioning only (for example, increase of } \\
\text { vocational training by five hours/week); symptom aims, for } \\
\text { example, pain reduction, were excluded [ } 14] \text {. } \\
\text { 3. Means of reaching the aims (for example, increase of vocational } \\
\text { training I/2 hour/day week I, I hour/day w. } 2 \text { etc.). }\end{array}$ & At the start of the action phase. \\
\hline Team & Check-up conferences produced fresh partial aims. & I/3 - 4 weeks. \\
\hline
\end{tabular}

Team member (usually the physiotherapist) Vocational conferences with the employer and a clerk from the Social Insurance Agency or, for unemployed patients, the Employment Office.

\begin{tabular}{lll}
\hline Physician & Handling of the sick-listing. & $1 / 3-4$ weeks. \\
\hline Physiotherapist & Completion of graded activity. Check-ups less frequent. & $1 / 3-4$ weeks. \\
\hline Health-care adviser & Completion of education in applied relaxation. & I/week (f. $6-8$ w.) \\
\hline $\begin{array}{l}\text { Psychologist or social worker } \\
\text { If needed: cognitive-behavioural therapy as support during the re- }\end{array}$ & I/week. \\
\hline
\end{tabular}

performed using PROC MIXED in SAS, version 9.1, and the results are presented as separate graphs for the subacute and chronic patients and as means with $95 \%$ confidence intervals and $p$-values, adjusted for all parameters (main effect and interactions).

The two patients who died (Figure 1) were excluded from the outcome analyses except from the Cox regression [31].
Visits at 18 months were analysed for those patients who had completed all the follow-up forms, while the mixedlinear model also included incomplete responders. To evaluate their possible influence on the treatment results, we also analysed the days of hospital care, the use of surgery for musculoskeletal disorders and multidisciplinary rehabilitation at units other than the rehabilitation centre. 


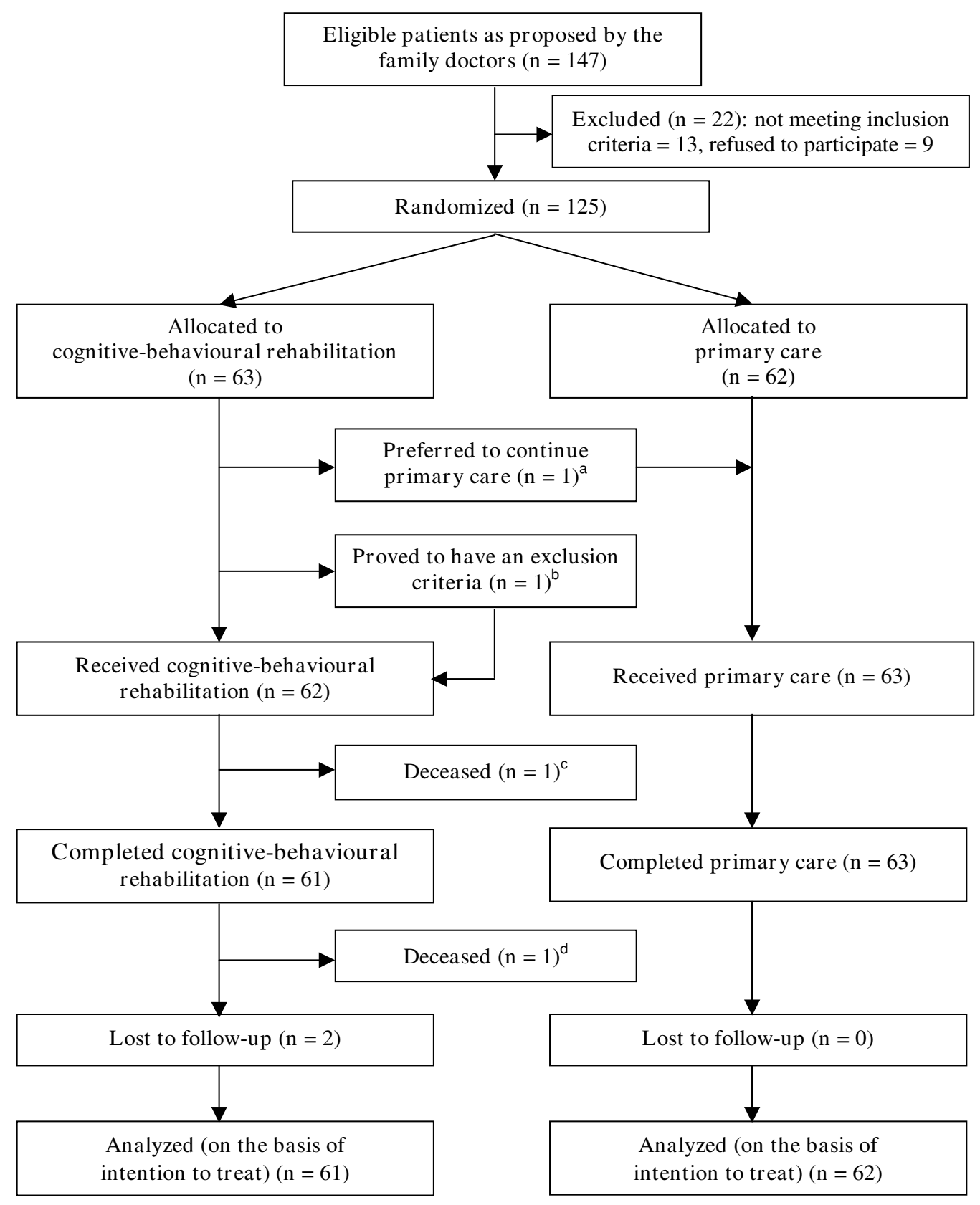

\footnotetext{
${ }^{\mathrm{a}}$ Woman, 58 (years), randomized to cognitive-behavioural rehabilitation, but preferred to continue at the health centre.

${ }^{\mathrm{b}}$ Male, 45 , incorrectly included: except BNP, he suffered from whiplash-associated disorders that during the initial mapping out (Table 1) showed to be a primary obstacle to working.

${ }^{c}$ Male, 55, died 12 months after inclusion from lung cancer.

${ }^{d}$ Male, 53, died 11 months after inclusion of a reason which was unknown to us. All these four patients had chronic BNP.
}

\section{Figure I}

Flowchart. 
The analyses were performed on an intention-to-treat basis. The primary outcome measure was also subjected to a per-protocol analysis [33]. The total percentage of withdrawals and drop-outs was calculated. This sum should not exceed 30\% [34]. Baseline characteristics of responders and non-responders were compared. A $p$-value $<.05$ or, concerning the Cox regression, a 95\% confidence interval not including 1.00, was considered statistically significant. Except for the mixed linear models, analyses were performed using Stata, 9.1.

\section{Blinding}

The analyst of the sick-listing data was blind to the intervention alternative. Blinding was not possible for the other outcomes. For example, which of the two interventions was offered could not be concealed from either the care providers or the patients.

\section{Data collection}

The sick-listing data were provided by the Stockholm County Social Insurance Agency. Data concerning the rehabilitation centre were collected from the medical records of the centre. Primary care and other health-care data were obtained from follow-up forms. Although these self-report measures have been used successfully in previous research, their reliability and validity have not been established. However, because the patients were free to seek treatment at any other facility, the only comprehensive sources of health-care data were self-ratings [9]. The data were fed into a specially designed database using Access version 2000.

\section{Power calculation}

To calculate the power, a preliminary study was performed. In this retrospective study, 172 consecutive patients with subacute and chronic BNP, who completed rehabilitation at the centre during the period 1996 2000 , were included. The mean rehabilitation period was 266 (SD \pm 170$)$ days. The Return-to-work share was $76 \%$; for subacute and chronic BNP 89\% and 73\%, respectively $(p<.05)$. The power calculation was based on this preliminary study and a forecast of the probability of return-towork after traditional care for BNP [35]. The forecast probability for the patients in the preliminary study was calculated from their current sick-listing at baseline. It proved to be $49 \%$, i.e. 27 percentage units less than the actual rate of $76 \%$. Including an uncertainty about the application of this forecast to our patient sample, we expected to reach a difference between the rehabilitation group and the primary-care group of at least 22 percentage units. With an alpha of .05 and a power of $80 \%$, this should require the inclusion of 154 patients; or, to allow a reasonable dropout rate, 170 patients.

\section{Inclusion procedure}

For the patients who fulfilled the criteria, the family doctor gave verbal and written information about the project. Each patient who gave his or her oral consent to participate to the family doctor was interviewed by telephone by a research assistant within two days. The patients who still qualified for the study saw the assistant at the health centre within five days. At the appointment, the patient signed an informed consent to participate and went through an initial form including, among other items, the baseline characteristics in Table 2 . Then the assistant carried out, among other tests, a lift test [36]. The reliability of that test procedure was confirmed in a separate study [37]. After stratification by age ( $\leq 44 / \geq 45$ years) and subacute/chronic BNP, the assistant performed the randomization. The two treatment alternatives were distributed in opaque envelopes by a computerized block-randomization procedure produced by an independent statistician. The assistant opened the remaining envelope with the lowest random number and presented the content to the patient.

\section{Ethical approval}

Approval for the study was given by The Research Ethics Committee, Karolinska University Hospital, Huddinge.

\section{Premature cessation of recruitment}

The recruitment of participants started in August 2000 and was discontinued in January 2004, when 125 patients were included. The reason was the opening in April 2004 of a large back-rehabilitation centre in a neighbouring municipality (Nacka) on the initiative of the Stockholm County Social Insurance Agency and Stockholm County Council. We presumed that many future study patients who would be randomized to the primary-care group would be referred to that centre and would contaminate the primary-care branch of our study.

\section{Follow-up}

Six, 12 and 18 months after inclusion, the patients completed forms concerning, among other items, health-care utilization. If necessary, a postal reminder was sent after two weeks and a telephone reminder after another two weeks. If the forms were not returned despite these measures, the data were considered missing. The patient who was last to be included completed the 18-month followup period in July 2005.

\section{Results}

\section{Response rate and missing data}

Data for the baseline characteristics, sick-listing and care at the rehabilitation centre were complete. For other health-care data, the response rates for the six-, 12- and 18 -month forms in the rehabilitation group $(n=61)$ were $57(93 \%), 56(92 \%)$ and $55(90 \%)$ respectively and all 
Table 2: Baseline characteristics.

\begin{tabular}{|c|c|c|c|}
\hline & Rehabilitation group $(n=63)$ & Primary-care group $(n=62)$ & $p$-value \\
\hline Women & $33(52[40-65] \%)$ & 35 (56 [44 - 69]\%) & NS \\
\hline Age (years) & $42.2[39.8-44.6]$ & $43.0[40.4-45.7]$ & NS \\
\hline Neck-pain domination & $17(27[16-38] \%)$ & $21(34[22-46] \%)$ & NS \\
\hline Widespread (= back + neck) pain & $55(87[79-96] \%)$ & $45(73[61-84] \%)$ & .04 \\
\hline \multicolumn{4}{|l|}{ Pain score (VAS, 0 - 100; median (IQR))[48]: } \\
\hline "Just now" & $61(30)$ & $53(30)$ & NS \\
\hline "Worst last week" & $77(29)$ & $73(26)$ & NS \\
\hline \multicolumn{4}{|l|}{ Health-related quality of life (EQ-5D)[49] } \\
\hline (median (IQR)) & $.489(.332)$ & $.497(.332)$ & NS \\
\hline Immigrants (= born outside Sweden) & $19(30[19-42] \%)$ & $15(24[13-35] \%)$ & NS \\
\hline Single life & $19(30[19-42] \%)$ & $21(34[22-46] \%)$ & NS \\
\hline Low education (= at most junior high school) & $37(60[47-72] \%)$ & 35 (56 [44- 69]\%) & NS \\
\hline Blue-collar work (of the non-unemployed) & $4 \mathrm{I}(87[77-97] \%)$ & 47 (87 [77 - 97]\%) & NS \\
\hline Unemployed & 14 (22 [12-33]\%) & $15(24[13-35] \%)$ & NS \\
\hline Previous sick-listing (days)* & $223[189-257]$ & $222[188-256]$ & NS \\
\hline \multicolumn{4}{|l|}{ Lifting capacity (kg; mean): } \\
\hline PILE lumbar [36] & $12.3[10.4-14.2]$ & $12.4[10.3-14.6]$ & NS \\
\hline PILE cervical [36] & $11.5[9.7-13.3]$ & $11.6[9.6-13.6]$ & NS \\
\hline
\end{tabular}

Descriptive statistics. The $95 \%$ confidence intervals are shown within brackets. Bold figures indicate a significant difference.

NS = Non-significant; IQR = Inter-quartile-range.

$*=$ Net days over the 18 months preceding baseline.

forms were answered by 51 patients (84\%). The corresponding rates for the primary-care group $(\mathrm{n}=62)$ were $50(81 \%), 48(77 \%), 50(81 \%)$ and $42(68 \%)$. Nonresponders and responders are compared in Table 3.

\section{Baseline characteristics and participant flow}

Except for a higher prevalence of widespread pain in the rehabilitation group, there were no significant differences (Table 2). When analyzed separately (data not shown), the subacute rehabilitation-group patients were equal to the subacute primary-care-group patients while the chronic rehabilitation-group patients had a much higher prevalence of widespread pain: 93 [85 - 100]\% versus 68
[54-82]\% for the chronic primary-care-group patients ( $p$ $=.004)$.

Patients who were allocated to the rehabilitation group started the programme within one week. Patients who were allocated to the primary-care group continued care at their health-centres. Sixty-one patients in the rehabilitation group completed cognitive-behavioural rehabilitation; all primary-care-group patients completed primary care (Figure 1). The two deceased rehabilitation-group patients had passed the "red-flags" examinations [12] at the start without remark. 
Table 3: Missing data.

\begin{tabular}{|c|c|c|c|c|c|c|c|}
\hline Follow-up & Six months & $p$-value & 12 months & $p$-value & 18 months* & All forms & $p$-value \\
\hline \multicolumn{8}{|l|}{ Rehabilitation group $(n=6 I)$} \\
\hline Previous sick-listing (days) ${ }^{* *}$ & 397 vs. 215 & .008 & 371 vs. 214 & .01 & - & - & \\
\hline Current sick-listing at baseline (days) & 367 vs. 158 & $<.001$ & 346 vs. 156 & $<.001$ & - & 275 vs. 151 & .003 \\
\hline Unemployment (\%) & - & - & 60 vs. 18 & .03 & - & - & \\
\hline \multicolumn{8}{|l|}{ Primary-care group $(n=62)$} \\
\hline Age (years) & 35.8 vs. 44.8 & .006 & - & & - & 38.3 vs. 45.3 & .01 \\
\hline Single (\%) & 58 vs. 28 & .046 & - & & - & - & \\
\hline EQ-5D [49] & - & - & .357 vs. .562 & .046 & - & - & \\
\hline
\end{tabular}

Non-responders versus responders. Significant differences at baseline. Descriptive statistics.

*At 18 months there were no significant differences.

$* *=$ Net days over the 18 months preceding baseline.

\section{Outcome measures}

\section{Return-to-work share}

There were no significant differences between the rehabilitation group and the primary-care group, or between the subacute and chronic patients considered separately (Table 4). In both the rehabilitation group and the primary-care group, most of the patients who regained any degree of work ability returned to full-time work: 20/35 (57\%) and 25/35 (71\%) respectively (non-significant). The mean degrees of work ability at return to work were $.77[.67-.87]$ and $.85[.76-.94]$ respectively (non-significant).

Return-to-work chance

The hazard ratio for the rehabilitation group increased over the three six-month periods in comparison to the primary-care group, but the difference did not reach significance (Table 5). The subacute rehabilitation-group patients showed a substantial increase over these periods and achieved a significantly higher hazard ratio at 18 months than the subacute primary-care-group patients. There were no differences for the chronic patients.
Net days

At 18 months there were no significant differences between the treatment groups, or between the subacute and chronic patients considered separately (Table 4). Over the three six-month periods, the decrease was significantly more rapid for the whole rehabilitation group and for the subacute rehabilitation-group patients considered separately (bottom of Figure $2 a-b$ ). In the first six-month period, there were 50 more Net days for the subacute rehabilitation-group patients; in the third period there were 31 days fewer (Figure 2a). There were no differences for the chronic patients (Figure 2b). Adjustment for widespread pain showed no changes.

\section{Visits}

At 18 months there were no significant differences between the treatment groups or between the subacute and chronic patients considered separately (Table 4). Over the three six-month periods, the decrease was significantly more rapid for the whole rehabilitation group (bottom of Figure $3 \mathrm{a}-\mathrm{b}$ ). For the subacute patients, the rehabilitation group showed a continuously decreasing

Table 4: Return-to-work share, Net days and Visits.

\begin{tabular}{llll}
\hline & Patients & Rehabilitation group & Primary-care group \\
\hline Return-to-work share (\%) & All & $35 / 61(57[45-70])$ & $35 / 62(57[44-69])$ \\
& Subacute & $18 / 20(90[76-104])$ & $15 / 18(83[64-102])$ \\
& Chronic & $17 / 41(42[26-57])$ & $20 / 44(46[30-61])$ \\
\hline \multirow{2}{*}{ Net days } & All & $397[354-440]$ & $391[345-436]$ \\
& Subacute & $327[261-392]$ & $292[194-391]$ \\
& Chronic & $431[377-486]$ & $431[383-478]$ \\
\hline \multirow{2}{*}{ Visits } & All & $55.7[49.3-62.2]$ & $52.0[38.1-66.0]$ \\
& Subacute & $48.3[38.5-58.1]$ & $40.6[23.1-58.1]$ \\
& Chronic & $60.1[51.6-68.7]$ & $56.6[38.1-75.2]$ \\
\hline
\end{tabular}

Point estimates at 18 months. Descriptive statistics. 
Table 5: Return-to-work chance.

\begin{tabular}{llll}
\hline Rehabilitation group & Six months & 12 months & 18 months \\
\hline All patients $(n=61)$ & $.9[.6-1.4]$ & $1.2[.7-2.0]$ & $1.6[.7-3.6]$ \\
Subacute patients $(n=20)$ & $.9[.5-1.6]$ & $1.8[.8-3.9]$ & $3.5[1.001-12.2]$ \\
Chronic patients $(n=41)$ & $.9[.5-1.6]$ & $.9[.4-2.1)$ & $1.0[.3-3.9]$ \\
\hline
\end{tabular}

Cox regression for recurrent events. Hazard ratios for the rehabilitation group as compared with the primary-care group with $95 \%$ confidence intervals. Significant differences in bold figures.

trend while the primary-care group showed a substantial decrease between the first and second six-month periods but no further reduction (Figure 3a). For the chronic patients, the rehabilitation group showed a continuous decrease while the primary-care group showed no reduction (Figure 3b). Visits were substantially more numerous for both the subacute and chronic rehabilitation-group patients during the first period, but there were around half as many in the third period. However, there was no significant difference in the rate of decrease between the subacute and chronic patients considered separately (bottom of Figure 3a-b). Adjustment for widespread pain gave no changes.

\section{Interventions}

Cognitive-behavioural rehabilitation

Cognitive-behavioural rehabilitation over 18 months included 45.1 [39.2 - 50.9] consultations. Most of the consultations took place in the first six-month period, followed by a rapid reduction (Figure 4). Totalling $0-18$ months, the most and second most frequent consultations were with a physician (16.6 [14.4 - 18.7]) and a physiotherapist (12.3 [10.5 - 14.1]). A detailed description of the rehabilitation programme is shown in Table 6.

\section{Primary care}

For the rehabilitation group, primary care over 18 months comprised 11.7 [6.7 - 16.7] consultations. After a slight increase from the first to the second six-month period, there was stagnation (Figure 4). During the first six-month period most of the rehabilitation-group patients $(41 / 57$ $(72 \%))$ had no primary-care consultations at all.

For the primary-care group, primary care over 18 months included 50.9 [37.5 - 64.3] consultations. After a slight decrease from the first to the second six-month period there was no further reduction (Figure 5). Totalling $0-18$ months, the most and second most frequent consultations were with a physiotherapist (28.9 [19.4 - 38.4]) and a physician (12.4 [10.2 - 14.7]).

\section{Other treatment efforts}

Hospital care was received by the rehabilitation group and the primary-care group for $1.2[-.2-2.6]$ days and $.8[.1-$ 1.6] days respectively, surgery for musculoskeletal disor- ders by $1 / 51(2[-2-6] \%)$ and 3/43 (7 [-1 - 15]\%) respectively, and multidisciplinary rehabilitation at other units than the rehabilitation centre by $1 / 50(2[-2-6] \%)$ and $4 / 43(9[0-18] \%)$ respectively. The differences were nonsignificant.

\section{Per-protocol analysis}

When the incorrectly included rehabilitation-group patient (Figure 1, footnote b) was excluded from the analyses and the rehabilitation-group patient who preferred to continue primary care (Figure 1) was counted with the primary-care group, the Return-to-work share increased to 44 [28 - 59]\% for the chronic rehabilitation-group patients, and decreased to 44 [30 - 59]\% for the chronic primarycare-group patients. This differed only marginally from the intention-to-treat analyses.

\section{Discussion}

This randomized controlled trial concerned primary-care patients with subacute and chronic BNP. A programme of cognitive-behavioural rehabilitation was compared with continued primary care. The results were equivalent over 18 months. However, analyses of the three component six-month periods indicated that the rehabilitation programme might be superior to primary care in the longer run, especially for subacute patients.

\section{Sick-listing}

Why was the Return-to-work share substantially lower than expected for the rehabilitation group and higher than expected for the primary-care group? According to Englund et al. [38], sick-listing in Swedish primary care might depend more on the patient's wishes than on guidelines: even when the family doctor did not recommend sick-listing, a certificate was issued in $87 \%$ of cases. In view of this, what explains the substantial underestimation of the Return-to-work share for the primary-care group (49\% vs. the actual share of 57\%)? One explanation might be a project that was initiated by the Swedish government in 2002 to halve the extent of sick-listing by 2008 [39]. The focus has been on applying more restrictions in the social insurance system, including failing an increasing number of sick-listing certificates, while the resources for multidisciplinary rehabilitation have been even scarcer than before $[40,41]$. Anyhow, the low Return-to-work share in 
a. Subacute patients.
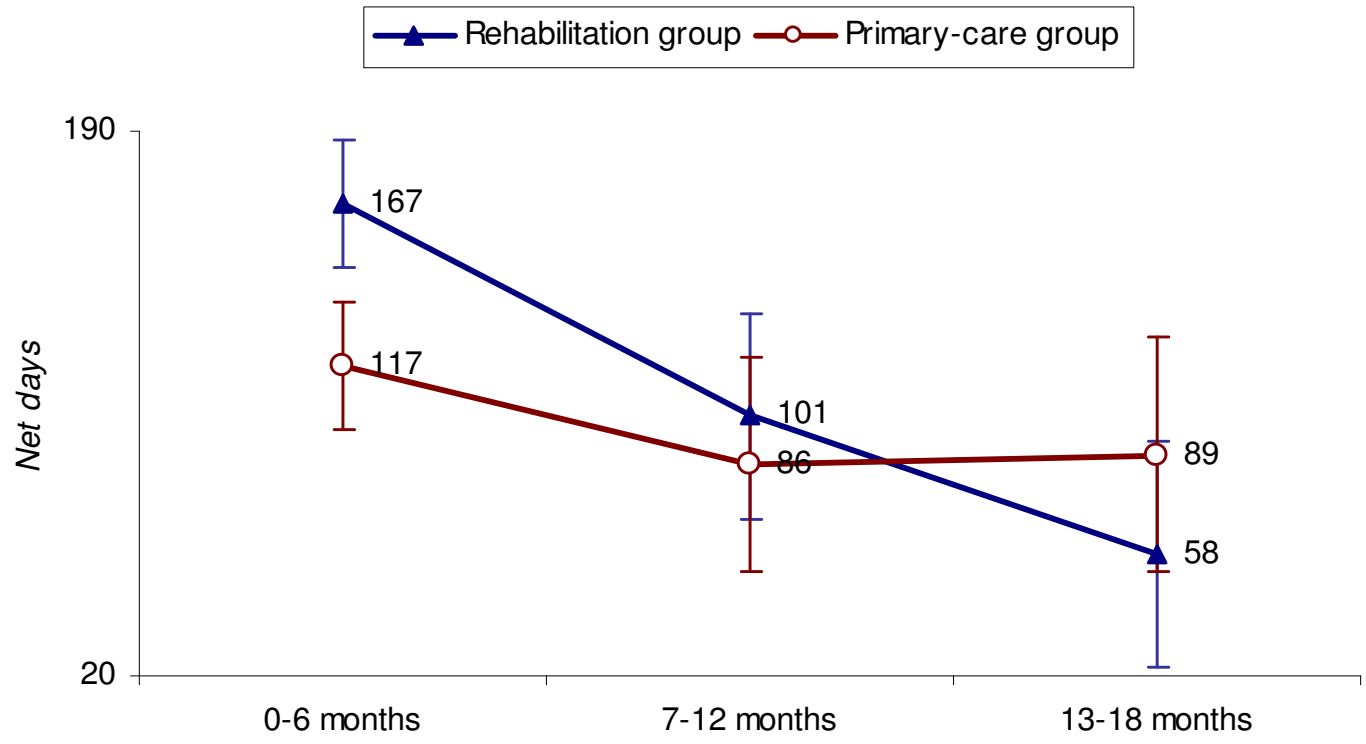

b. Chronic patients.
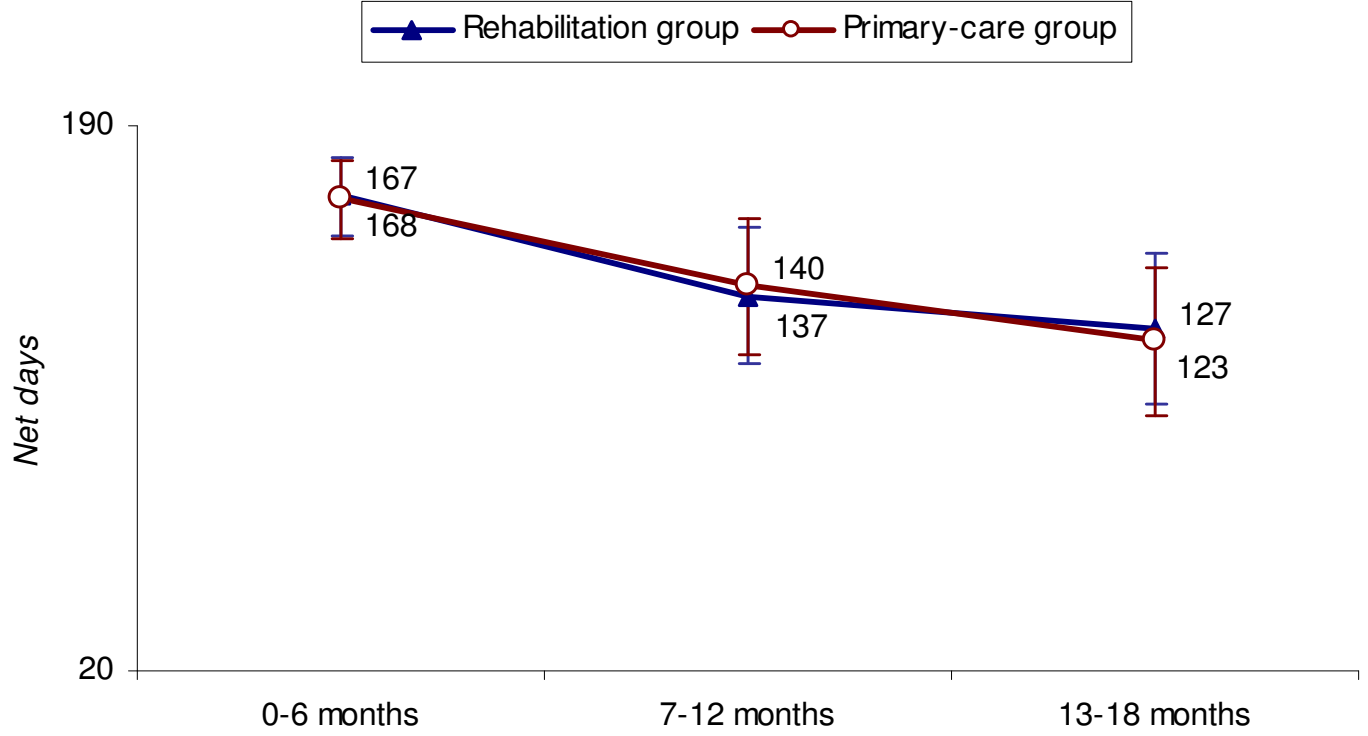

Time (first, second or third six-month period): $p<.001$.

Rehabilitation group or primary-care group: NS.

Subacute or chronic: $p<.001$.

Time $\mathrm{x}$ rehabilitation group or primary-care group: $p=.008$.

Time $\mathrm{x}$ rehabilitation group or primary-care group $\mathrm{x}$ subacute or chronic: $p<.001$.

Figure 2

a - b. Net days. Mixed linear model. In the diagrams, $95 \%$ confidence intervals are included. At the bottom the explanatory variables and their $p$-values are shown. Bold figures indicate a significant difference. NS = non-significant. 
a. Subacute patients.
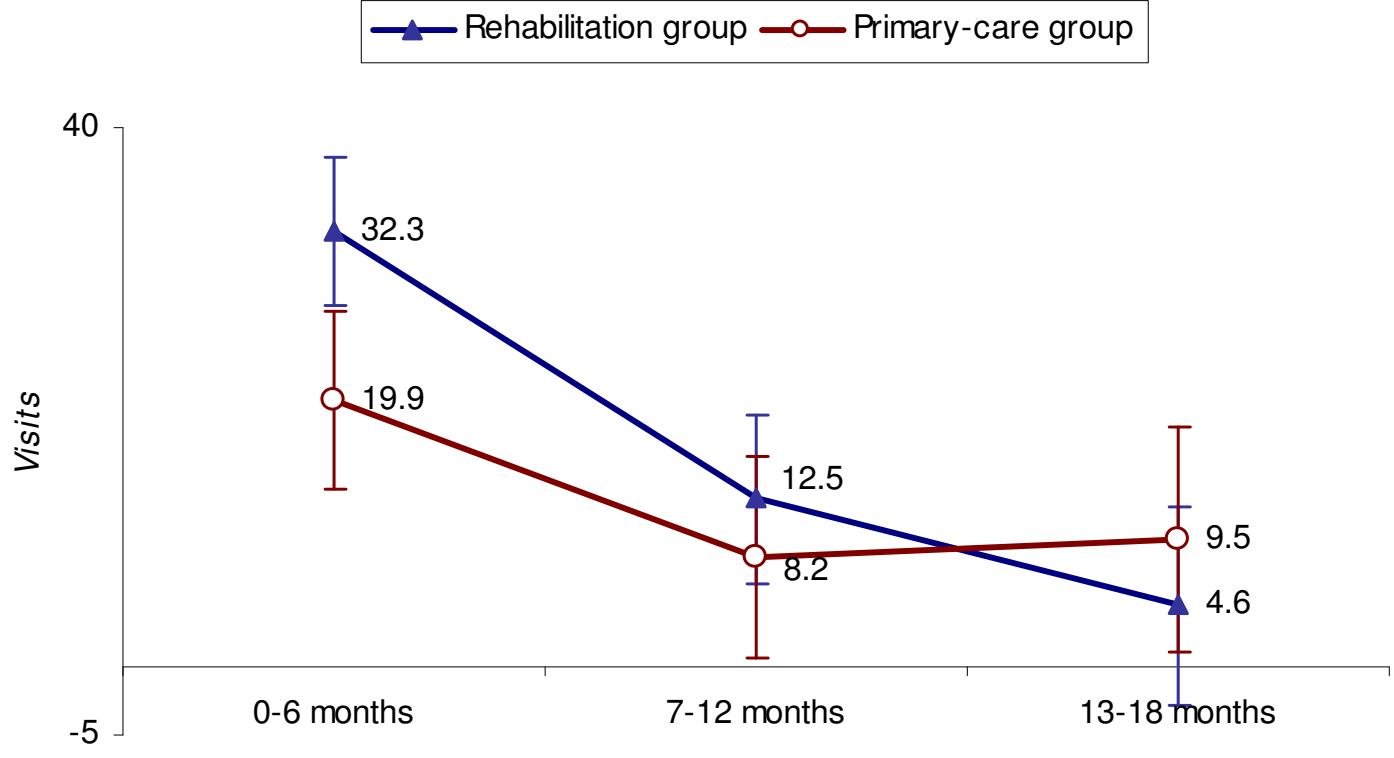

b. Chronic patients.
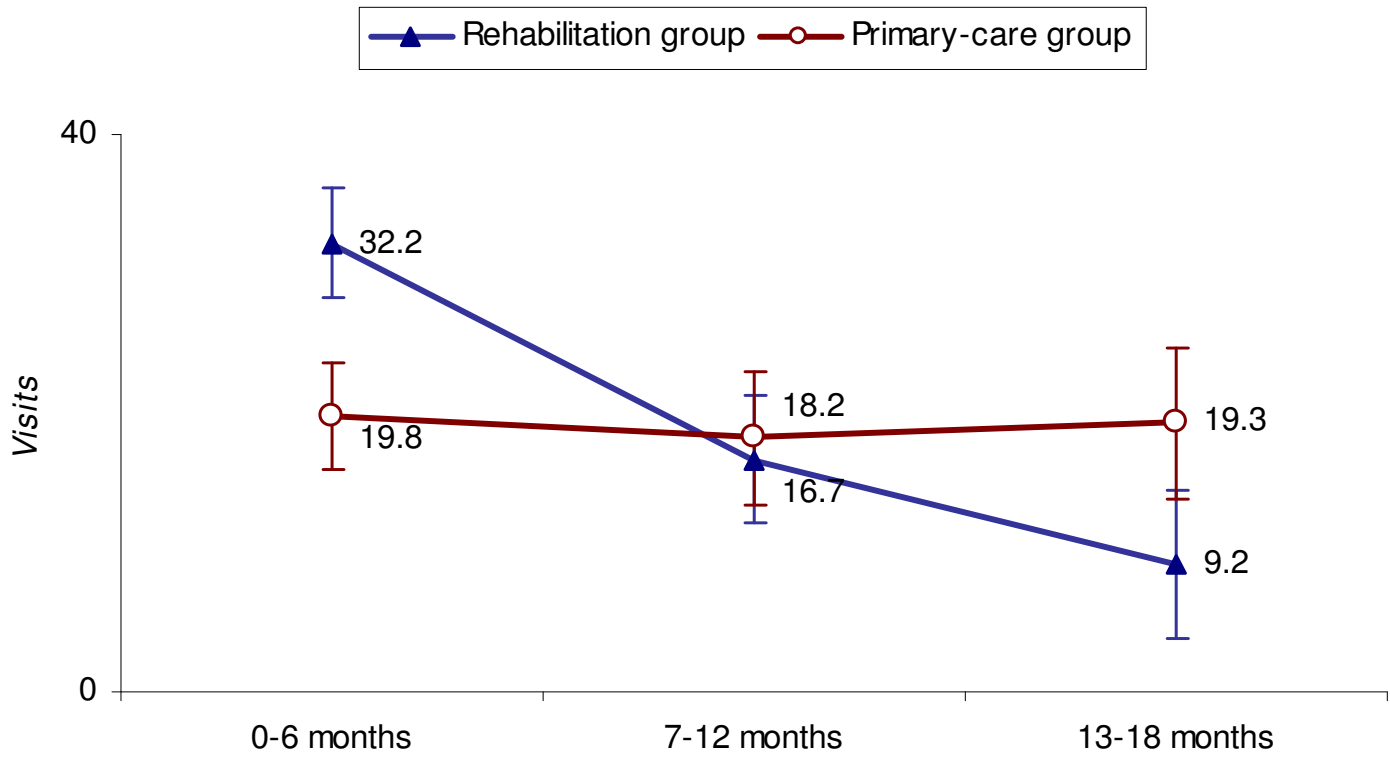

Time (first, second or third six-month period): $p<.001$.

Rehabilitation group or primary-care group: NS.

Subacute or chronic: NS.

Time $\mathrm{x}$ rehabilitation group or primary-care group: $p<.001$.

Time $\mathrm{x}$ rehabilitation group or primary-care group $\mathrm{x}$ subacute or chronic: NS.

Figure 3

a - b. Visits. Mixed linear model. Further explanations in Figure $2 a-b$. 
Table 6: Cognitive-behavioural rehabilitation.

\begin{tabular}{|c|c|c|c|c|}
\hline \multirow[t]{3}{*}{$\begin{array}{l}\text { Rehabilitation period } \\
\text { (days) }\end{array}$} & $\begin{array}{l}\text { Total period } 328( \pm 195) \\
\text { median } 283(\text { IQR2 } 15)\end{array}$ & \multicolumn{2}{|c|}{$\begin{array}{l}\text { Investigation and treatment phase } 42( \pm 18) \text {; median } \\
40 \text { (IQR22) }\end{array}$} & \multirow[t]{2}{*}{$\begin{array}{l}\text { Action phase } 287( \pm 193) \\
\text { median } 249(\text { IQR232) }\end{array}$} \\
\hline & \multicolumn{3}{|c|}{ Consultations } & \\
\hline & One-to-one & Treatment measure & At conferences & In total \\
\hline \multirow[t]{3}{*}{ Physician } & $7.3( \pm 5.2)$ & $\begin{array}{l}\text { Administration of sick-listing } \\
61 / 61(100 \%)\end{array}$ & $10.6( \pm 6.8)$ & $17.9( \pm 11.0)$ \\
\hline & & $\begin{array}{l}\text { Prescription of drugs } 53 / 61 \\
(87 \%)\end{array}$ & & \\
\hline & & $\begin{array}{l}\text { Cortisone injections } 9 / 61 \\
(15 \%)\end{array}$ & & \\
\hline \multirow[t]{2}{*}{ Physiotherapist } & $7.8( \pm 4.9)$ & Graded activity $61 / 61$ (100\%) & $4.6( \pm 3.4)$ & $12.4( \pm 7.1)$ \\
\hline & & $\begin{array}{l}\text { Orthopaedic manual therapy } \\
\text { I5/6I (25\%) }\end{array}$ & & \\
\hline $\begin{array}{l}\text { Psychologist or social } \\
\text { worker }\end{array}$ & $4.8( \pm 5.2)$ & $\begin{array}{l}\text { Cognitive-behavioural } \\
\text { therapy } 58 / 61 \text { ( } 95 \%)\end{array}$ & $3.4( \pm 3.0)$ & $8.2( \pm 7.8)$ \\
\hline Health-care adviser & $6.2( \pm 4.8)$ & $\begin{array}{l}\text { Applied relaxation } 48 / 61 \\
(79 \%)\end{array}$ & $.3( \pm .8)$ & $6.6( \pm 5.3)$ \\
\hline \multicolumn{5}{|l|}{ Conferences: } \\
\hline Team conferences & $8.6( \pm 5.7)$ & & & \\
\hline $\begin{array}{l}\text { Vocational conf. } \\
\text { (incl. workpl. visits) }\end{array}$ & $2.4( \pm 2.4)$ & $\begin{array}{l}\text { Vocational training } 32 / 61 \\
(52 \%)\end{array}$ & & \\
\hline $\begin{array}{l}\text { Sum of treatment } \\
\text { occasions }\end{array}$ & $37.1( \pm 19.2)$ & & Sum of consultations & $45.1( \pm 22.8)$ \\
\hline \multicolumn{5}{|l|}{$\begin{array}{l}\text { Physical activity (days/ } \\
\text { week): }\end{array}$} \\
\hline Exercise programme & $5.5( \pm 2.2)$ & & & \\
\hline Gym training & $1.0( \pm 1.3)$ & & & \\
\hline
\end{tabular}

Specification of measures. Number of consultations (mean (SD)) unless otherwise stated.

$\mathrm{SD}=$ Standard deviation; IQR = Inter-quartile range.

the rehabilitation group was disappointing, and even if the primary-care group had shown as low a Return-to-work share as predicted, the difference between the groups would have remained non-significant.

However, when subacute and chronic patients were analysed separately, a different picture emerged: the Return-towork share for the subacute rehabilitation-group patients was as expected, but the share for the chronic rehabilitation-group patients was far lower. The significantly better Return-to-work chance at 18 months and the more rapid reduction in Net days among the subacute rehabilitationgroup patients highlighted this. Previous research supports the view that cognitive-behavioural interventions at an early stage of disabling BNP can prevent long-term disability $[9,10,14,42]$, while the effect on sick-listing is more doubtful for chronic back pain. Schonstein et al. [43] concluded that physical conditioning programs with a cognitive-behavioural and work-related approach reduced sick- listing, whereas another Cochrane review revealed that behavioural-rehabilitation programmes had no better effect on sick-listing for chronic back pain than active conservative treatment [20].

What components of our programme could explain its possible superiority in the long run for subacute patients? Previous research on graded activity had an occupationalcare setting and concerned subacute patients only $[7,8,14,18,44,45]$. Two earlier studies $[7,14]$ found that graded activity in multidisciplinary contexts decreases sick-listing. Two later studies $[18,44]$ contradicted that. Steenstra et al. [18] found that workplace interventions alone reduced sick-listing, while graded activity alone or in combination with workplace interventions did not. One explanation might be that the earlier studies were performed in specialised in-company clinics by a limited number of physiotherapists, including some of the researchers, while the study by Steenstra et al. also 


\section{Physician $\square$ Physiotherapist $\square$ Psychologist/social w orker* $\square$ Health-care adviser $\square$ Other staff**}

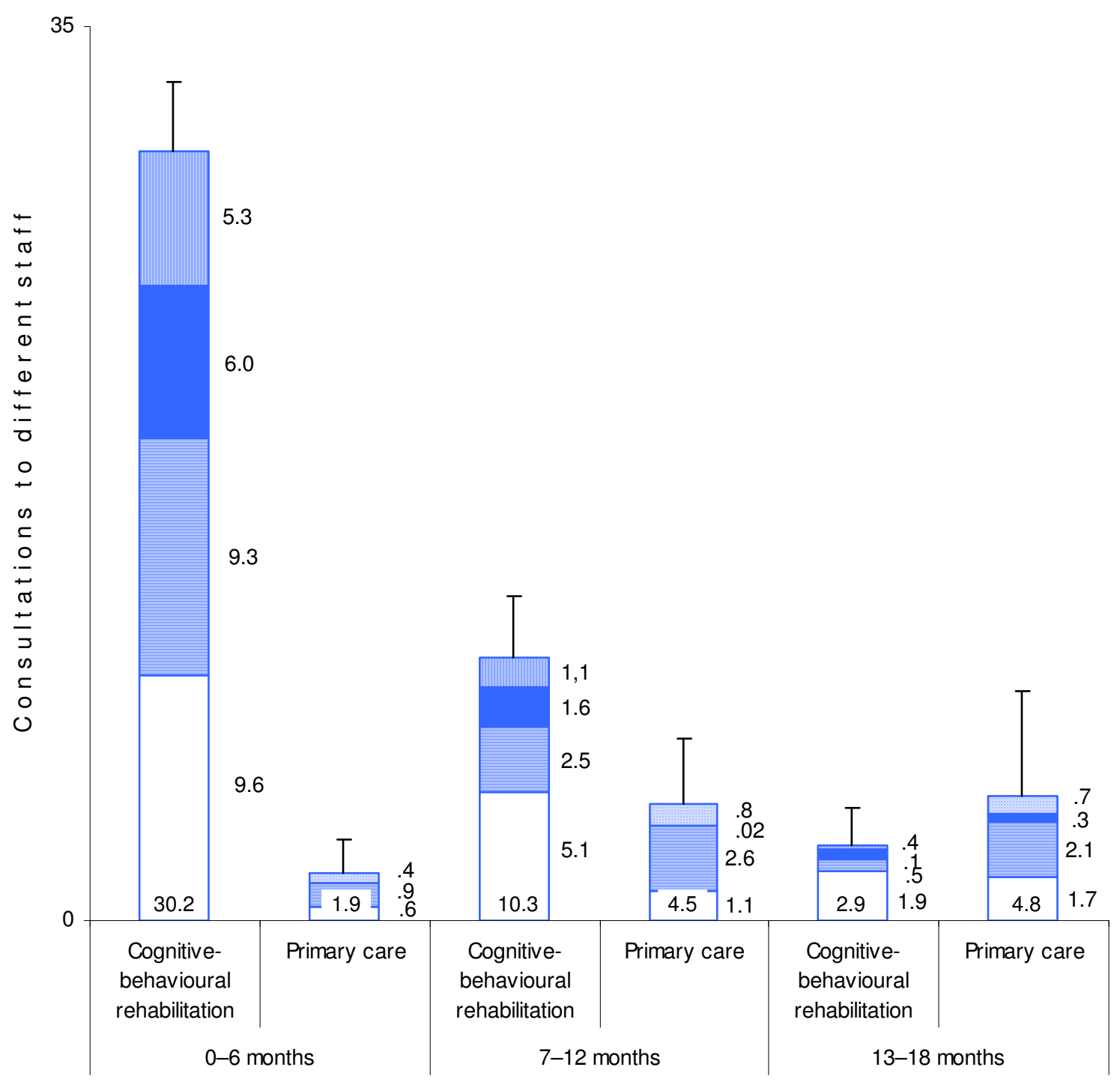

*Concerning primary care, social worker was the only option.

**= Occupational therapist, nurse, X-ray/MRI staff, laboratory personnel, and complementary-medicine staff (for example, masseur and "Chinese doctor").

\section{Figure 4}

Consultations to different care staff for the rehabilitation group. For the total number (presented at the bottom of the staples), 95\% confidence intervals (upper part) are shown. 


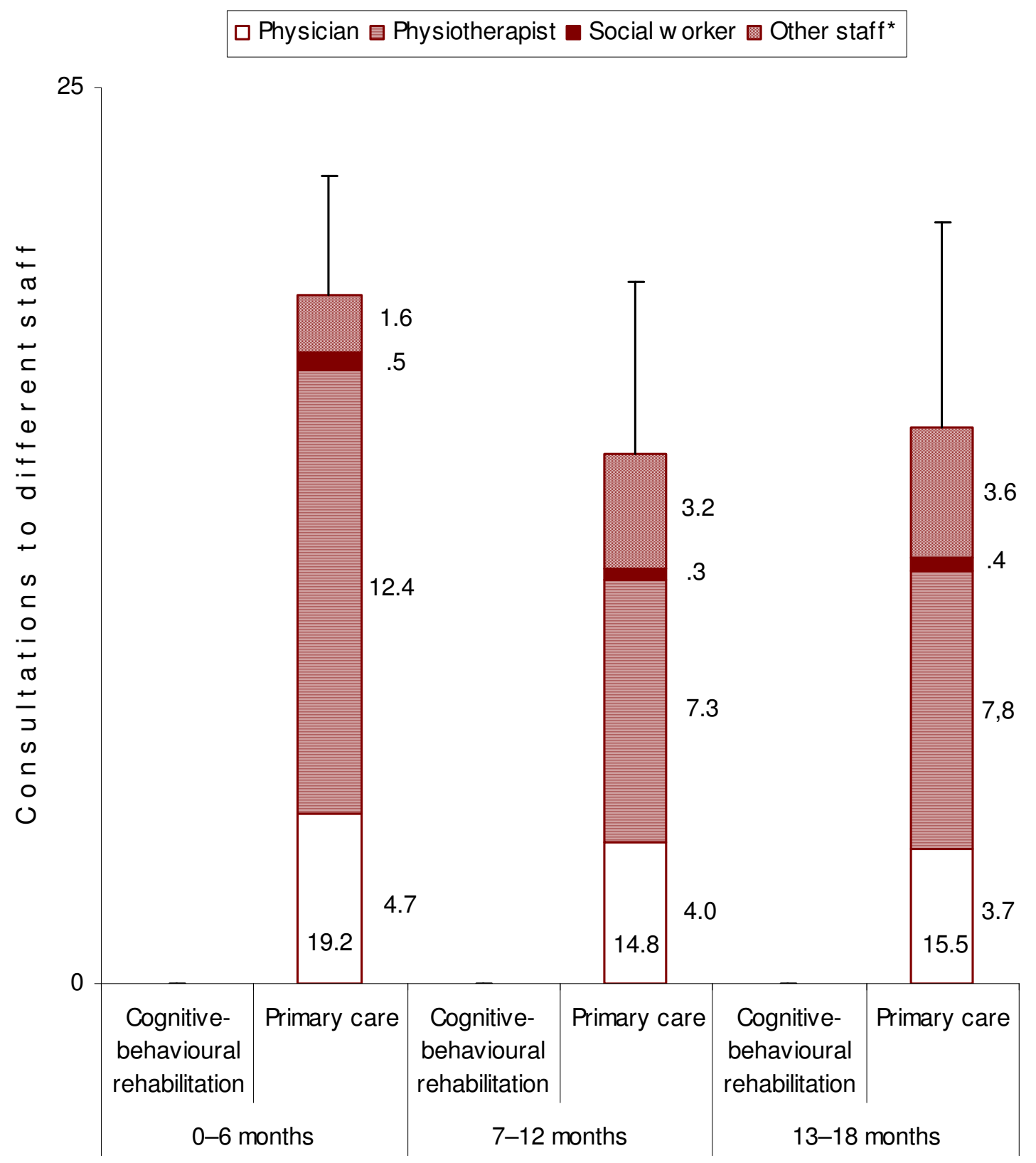

*= Occupational therapist, nurse, X-ray/MRI staff, laboratory personnel, and complementarymedicine staff (for example, masseur and "Chinese doctor")

\section{Figure 5}

Consultations to different care staff for the primary-care group. Further explanations in Figure 4. 
included out-company clinics with many physiotherapists who had received additional training [18]. These sixmonth results were confirmed at a 12-month follow-up [8]. Heymans et al. [44] found that standard care plus a low-intensity back school of eight hours was superior to standard care alone, while standard care plus a high-intensity graded-activity-like back school tended to be inferior. The follow-up period of those later studies did not exceed 12 months. In our study, however, the better sick-listing trend for the subacute rehabilitation-group patients was not obvious until after 12 months. Thus, the possibility that a longer period of graded activity has a positive effect on sick-listing for subacute patients in a primary-care setting could not be excluded from those later studies. As to the rest of our specific cognitive-behavioural elements (therapy by a psychologist or a social worker and training in applied relaxation), earlier conclusive studies are lacking [46].

Unlike previous research on graded activity, we also included chronic BNP. Most of the rehabilitation-group patients $(43 / 63(68 \%))$ had a current sick-listing exceeding 12 weeks at baseline. Our programme did not reduce their sick-listing. Why? One reason could be its comparatively limited extent. Haldorsen et al. [16] showed that, for return-to-work, light multidisciplinary treatment was adequate for moderately-disabled but not for highly-disabled patients. For the latter group, extensive multidisciplinary treatment totalling 120 hours was required; the light programme was no better than standard care. Jensen et al. [19] showed that an extensive behavioural-rehabilitation programme (fully 120 hours) for long-term BNP in female patients reduced sick-listing while more limited efforts did not. Males, however, achieved no better results from the full-time programme than from a light programme or standard care. Quite recently, Staal et al. [45] found that moderately disabled subjects benefited more from graded activity than those with higher disability scores. These studies indicate that return-to-work for patients with chronic BNP, if it is ever possible, requires a more extensive concept than our programme.

Another reason could be methodological defects. Graded activity by the book includes: two sessions/week over a maximum of 3-6 months until lasting full-time return-towork, an early agreement with the patient on a return-towork date regardless of the actual pain on that particular day, and a hands-off approach $[7,18]$. As our patients were comparatively more disabled, we found it realistic to apply less frequent sessions to increase the likelihood of positive changes at the next session (there was also a lack of resources for more frequent sessions), no upper time limit (which is also in accordance with the original concept [14]), the possibility of part-time return-to-work, an individual agreement about the return date (early in the rehabilitation period for some patients, later for others) and, when needed, manual therapy and cortisone injections early in the rehabilitation period (however, the hands-off approach was applied to most (46/61 (75\%)) of our patients). Notwithstanding the logical reasons for most of our modifications, they might have contributed to the failure to decrease the sick-listing of the chronic patients. These discrepancies might also explain why the positive effect on the subacute rehabilitation-group patients was not seen until the third six-month period, while those patients had substantially more Net days during the first period. It has recently been pointed out that suboptimal rehabilitation items in the pre-phase of return-to-work entail the risk of a counterproductive effect [18].

\section{Health-care visits}

In total, the rehabilitation group had more consultations by a physician, which is more costly than other staff categories. However, the resources spent on the rehabilitation group in the first six-month period were balanced by fewer consultations in primary care and a trend towards fewer Visits in the long run. Also, although the differences were not significant, the rehabilitation group tended to experience less surgery and other multidisciplinary rehabilitation. For patients with subacute BNP, this agrees with Linton et al. [9], whose cognitive-behavioural interventions were followed by a decrease in health-care utilization. For patients with chronic BNP, our findings are consistent with a large review showing that cognitivebehavioural programs have a substantial positive impact on psychological and medical function but only a small impact on sick-listing [46].

\section{Strengths of the study}

The design of our study, a randomized controlled trial, is the gold standard for evaluating treatment methods for back and neck pain [2].

The sick-listing data were complete. We also consider the health-care data to be acceptably representative. The response rate was higher than $80 \%$ except at 12 months, when it was nearly $80 \%$ for the primary-care group. Even when the missing data for the two deceased patients were included, the rehabilitation group met drop-out criteria [34]. For the primary-care group, Visits over 18 months should be interpreted with some caution as $32 \%$ were non-responders, but in other respects the follow-up rate of the primary-care group was also satisfactory. The nonresponders in the rehabilitation group had characteristics that may have increased health-care use (longer sick-listing periods and higher unemployment). In the primarycare group the non-responders were younger, which could have decreased utilization, whereas the lower healthrelated quality of life could possibly increase utilization. 
However, for the great majority, there were no significant differences at baseline between the non-responders and responders.

\section{Limitations of the study}

The inclusion plan was not fulfilled. A possible consequence may have been that some differences between the groups could not be demonstrated. However, certain differences in favour of the rehabilitation group were clear with the number of patients actually included.

Comparison of health-care visits gives only a limited idea of cost effectiveness. A complete health-economic evaluation is planned in a future study, including a cost-benefit analysis in which the direct costs (mainly of the interventions themselves), the indirect costs (mainly of the sicklisting), and the health-related quality of life are compared [47].

The primary outcome measure showed no difference. Notwithstanding the positive trends in favour of the rehabilitation group, especially for the subacute patients, Net days and Visits were also equivalent over 18 months. As differences in the results of various interventions tend to even out after 12 - 18 months [19], more conclusive results might require a longer follow-up period than in this study.

\section{Conclusion}

For patients with subacute and chronic BNP, cognitivebehavioural rehabilitation was compared with primary care. The results were equivalent over 18 months. However, there were indications that cognitive-behavioural rehabilitation in the longer run might be superior. For subacute BNP, it might be superior in terms of both sicklisting and health-care visits; for chronic BNP, in terms of health-care visits only. More conclusive results concerning this possible long-term effect might require a longer follow-up.

\section{Competing interests}

The authors declare that they have no competing interests.

\section{Authors' contributions}

OL was the main investigator, carried out the study, performed the analysis, and drafted the manuscript. SEJ contributed to the statistical analysis. LES, as supervisor for $\mathrm{OL}$, participated in all phases of the study. All authors read and approved the final manuscript.

\section{Acknowledgements}

This study was supported by grants from the Stockholm County Social Insurance Agency, Stockholm County Council, Ministry of Health and Social Affairs, Vårdal Foundation, Cardionics and Pharmacia (now part of Pfizer).

\section{References}

I. Hansson T, Jensen I: Sickness absence due to back and neck disorders. Sickness absence - causes, consequences, and physicians' sickness-certification practice. Scand J Public Health 2004, 32(Suppl 63): $|09-| 5 \mid$.

2. Nachemson A: Introduction. In Neck and back pain. The scientific evidence of causes, diagnosis, and treatment Edited by: Nachemson A, Jonson E. Philadelphia: Lippincott, Williams \& Williams; 2000:I-I2.

3. Norlund A, Waddell G: Cost of back pain in some OECD Countries. In Neck and back pain. The scientific evidence of causes, diagnosis, and treatment Edited by: Nachemson A, Jonson E. Philadelphia: Lippincott, Williams \& Williams; 2000:42I-425.

4. Waddell G, Watson PJ: Rehabilitation. In Back Pain Revolution 2nd edition. Edited by: Waddell G. Edinburgh: Churchill Livingstone; 2004:37I-399.

5. Wasiak R, Young AE, Roessler RT, McPherson KM, van Poppel MN, Anema JR: Measuring return to work. J Occup Rehabil 2007, I7:766-78|.

6. Hazard RG, Fenwick JW, Kalisch SM, Redmond J, Reeves V, Reid S, Frymoyer JW: Functional restoration with behavioural support. A one-year prospective study of patients with chronic low-back pain. Spine 1989, 14:157-I6I.

7. Hlobil H, Staal JB, Twisk J, Köke A, Ariëns G, Smid T, van Mechelen $W$ : The effects of a graded activity intervention for low back pain in occupational health on sick leave, functional status and pain: I 2-month results of a randomized controlled trial. J Occup Rehabil 2005, I 5:569-580.

8. Anema JR, Steenstra IA, Bongers PM, de Vet HC, Knol DL, Loisel P, van Mechelen W: Multidisciplinary rehabilitation for subacute low back pain: graded activity or workplace intervention or both? A randomized controlled trial. Spine 2007, 32:29I-298.

9. Linton SJ, Nordin E: A 5-year follow-up evaluation of the health and economic consequences of an early cognitive behavioral intervention for back pain: a randomized, controlled trial. Spine 2006, 31:853-858.

10. Linton SJ, Ryberg M: A cognitive-behavioral group intervention as prevention for persistent neck and back pain in a nonpatient population: a randomized controlled trial. Pain 200I, 90:83-90.

II. Waddell G: The biopsychosocial model. In Back Pain Revolution 2nd edition. Edited by: Waddell G. Edinburgh: Churchill Livingstone; 2004:265-282.

12. Waddell G, van Tulder M: Clinical guidelines. In Back Pain Revolution 2nd edition. Edited by: Waddell G. Edinburgh: Churchill Livingstone; 2004:283-322.

13. Karjalainen $K$, Malmivaara A, van Tulder $M$, Roine $R$, Jauhiainen $M$, Hurri H, Koes B: Multidisciplinary biopsychosocial rehabilitation for neck and shoulder pain among working age adults. Cochrane Database Syst Rev 2003:CD002194.

14. Lindström I, Öhlund C, Eek C, Wallin L, Peterson LE, Fordyce WE, Nachemson A: The effect of graded activity on patients with sub-acute low back pain: a randomized prospective clinical study with an operant-conditioning behavioral approach. Phys Ther 1992, 72:279-293.

15. Loisel P, Lemaire J, Poitras S, Durand MJ, Champagne F, Stock S, Diallo B, Tremblay C: Cost-benefit and cost-effectiveness analysis of a disability prevention model for back pain management: a six year follow up study. Occup Environ Med 2002, 59:807-815.

16. Haldorsen EM, Grasdal AL, Skouen JS, Risa AE, Kronholm K, Ursin H: Is there a right treatment for a particular patient group? Comparison of ordinary treatment, light multidisciplinary treatment, and extensive multidisciplinary treatment for long-term sick-listed employees with musculoskeletal pain. Pain 2002, 95:49-63.

17. Indahl A, Haldorsen EH, Holm S, Reikeras O, Ursin H: Five-year follow-up study of a controlled clinical trial using light mobilization and an informative approach to low back pain. Spine 1998, 23:2625-2630.

18. Steenstra IA, Anema JR, Bongers PM, de Vet HC, Knol DL, van Mechelen W: The effectiveness of graded activity for low back pain in occupational healthcare. Occup Environ Med 2006, 63:718-725.

19. Jensen IB, Bergstrom G, Ljungquist T, Bodin L: A 3-year follow-up of a multidisciplinary rehabilitation programme for back and neck pain. Pain 2005, I I 5:273-283. 
20. Ostelo RW, van Tulder MW, Vlaeyen JW, Linton SJ, Morley SJ, Assendelft WJ: Behavioural treatment for chronic low-back pain. Cochrane Database Syst Rev 2005.

21. Turk DC, Rudy TE: Neglected topics in the treatment of chronic pain patients: Relapse, noncompliance, and adherence enhancement. Pain I991, 44:5-28.

22. Marklund S: Risk- och friskfaktorer. Sjukskrivning och rehabilitering i Sverige. In [In Swedish; English summary: Sickness Absenteeism and Vocational Rehabilitation in Sweden] RFV redovisar; 1997:6.

23. Jensen IB, Bodin L, Ljungquist T, Bergström G, Nygren Å: Assessing the needs of patients in pain: a matter of opinion? Spine 2000 , 25:2816-2823.

24. General practitioners Health and Ageing Factbook 2006. Chapter 7 - International comparisons [http://www.health.gov.au/internet/main/ publishing.nsf/Content/056CE2932CA4D49ICA257183008169E2/ \$File/2006\%20Health\%20and\%20Ageing\%20Factbook.pdf]. Australian Government. Department of health and ageing

25. Grunnesjö MI, Bogefeldt JP, Svärdsudd KF, Blomberg SI: A randomized controlled clinical trial of stay-active care versus manual therapy in addition to stay-active care: functional variables and pain. J Manipulative Physiol Ther 2004, 27:43 I-44I.

26. The Health and Medical Service Act ( I 982:763) 2003 [http:// sweden.gov.se/sb/d/574/a/23125;jsessionid=afUh3zB3N6v-]. Government Offices of Sweden: Ministry of Health and Social Affairs

27. Rae D: Getting better value for money from Sweden's healthcare system. Economics department working paper no. 443. OECD $2005 \quad$ [http://www.olis.oecd.org/olis/2005doc.nsf/ c707a7b4806fa95dcl 25685d005300b6/ f501081 ec882a6b8c 1257088002cdbb0/\$FILE/JT001898I2.PDF].

28. Arrelöv B, Borgquist L, Ljungberg $D$, Svärdsudd $K$ : The influence of change of legislation concerning sickness absence on physicians' performance as certifiers. A population-based study. Health Policy 2003, 63:259-268.

29. Altman DG: Comparing groups - continuous data. In Practical statistics for medical research Ist edition. London: Chapman \& Hall; 1991:179-228.

30. Altman DG: Comparing groups - categorical data. In Practical statistics for medical research Ist edition. London: Chapman \& Hall; 1991:229-276.

31. Kelly PJ, Lim LL: Survival analysis for recurrent event data: an application to childhood infectious diseases. Statist Med 2000, 19:13-33.

32. Brown H, Prescott R: Applied mixed models in medicine. Edinburgh: John Wiley \& Sons LTD; 2001:199-259.

33. Begg C, Cho M, Eastwood S, Horton R, Moher D, Olkin I, Pitkin R, Rennie D, Schulz KF, Simel D, Stroup DF: Improving the quality of reporting of randomized controlled trials. The CONSORT statement. JAMA 1996, 276:637-639.

34. van Tulder MW, Assendelft WJ, Willem JJ, Koes BW, Bouter LM: Method guidelines for systematic reviews in the Cochrane Collaboration Back Review Group for Spinal Disorders. Spine 1997, 22:2323-2330.

35. Waddell G: Low back pain: a twentieth century health care enigma. Spine 1996, 2 1:2820-2825.

36. Mayer TG, Barnes D, Nichols G, Kishino ND, Coval K, Piel B, Hoshino D, Gatchel RJ: Progressive isoinertial lifting evaluation. II. A comparison with isokinetic lifting in a disabled chronic low-back pain industrial population. Spine 1988, 13:998-1002.

37. Lindell O, Eriksson L, Strender LE: The reliability of a I0-test package for patients with prolonged back and neck pain: Could an examiner without formal medical education be used without loss of quality? A methodological study. BMC Musculoskel Disord 2007, 8:31.

38. Englund L, Svärdsudd K: Sick-listing habits among general practitioners in a Swedish county. Scand J Prim Health Care 2000 | 8:81-86.

39. Goals of public health Swedish; Mål för folkhälsan Governmental bill 2002/03:35 [http://fhi.se/upload/PDF/2004/omfhi/p200203 35.pdf]

40. Lidwall U: The Swedish Social Insurance Agency and vocational rehabilitation - active vocational rehabilitation measures and return to work. [In Swedish; summary in English] 2006 [http://forsakringskassan.se/filer/publikationer/pdf/ana0610.pdf] Stockholm: Social Insurance Agency

41. Bergendorff S: Rehabilitation - the history of a long period of suffering. [In Swedish; Rehabilitering - ett långt lidandes historia]. Commission of Inquiry on Social Insurance [In Swedish; Socialförsäkringsutred- ningen]. Samtal om socialförsäkring 2006:10 [http://www.kfs.net/ projekt/dokument/SOU lidande rehab.pdf]

42. Linton SJ, Boersma K, Jansson M, Svard L, Botvalde M: The effects of cognitive-behavioral and physical therapy preventive interventions on pain-related sick leave: a randomized controlled trial. Clin J Pain 2005, 2 I: I09-I I9.

43. Schonstein E, Kenny DT, Keating J, Koes BW: Work conditioning, work hardening and functional restoration for workers with back and neck pain. Cochrane Database Syst Rev 2003.

44. Heymans MW, de Vet HC, Bongers PM, Knol DL, Koes BW, van Mechelen W: The effectiveness of high-intensity versus lowintensity back schools in an occupational setting: a pragmatic randomized controlled trial. Spine 2006, 3 I: |075-1082.

45. Staal JB, Hlobil H, Köke AJ, Twisk JW, Smid T, van Mechelen W: Graded activity for workers with low back pain: who benefits most and how does it work? Arthritis Rheum 2008, 59:642-649.

46. Linton S]: Utility of cognitive-behavioral psychological treatments. In Neck and back pain. The scientific evidence of causes, diagnosis, and treatment Edited by: Nachemson A, Jonson E. Philadelphia: Lippincott, Williams \& Williams; 2000:36I-38I.

47. Goosens M, Evers S: Cost-effectiveness of treatment for neck and low back pain. In Neck and back pain. The scientific evidence of causes, diagnosis, and treatment Edited by: Nachemson A, Jonson E. Philadelphia: Lippincott, Williams \& Williams; 2000:399-419.

48. Wewers ME, Lowe NK: A critical review of visual analogue scales in the measurement of clinical phenomena. Res Nurs Health 1990, 13:227-236.

49. Hansson E, Hansson T, Jonsson R: Predictors for work ability and disability in men and women with low-back or neck problems. Eur Spine J 2006, I 5:780-793.

\section{Pre-publication history}

The pre-publication history for this paper can be accessed here:

http://www.biomedcentral.com/1471-2474/9/172/pre pub
Publish with Biomed Central and every scientist can read your work free of charge

"BioMed Central will be the most significant development for disseminating the results of biomedical research in our lifetime. "

Sir Paul Nurse, Cancer Research UK

Your research papers will be:

- available free of charge to the entire biomedical community

- peer reviewed and published immediately upon acceptance

- cited in PubMed and archived on PubMed Central

- yours - you keep the copyright
BioMedcentral 